\title{
ORBITAL TUMOURS
}

This was the subject for discussion at a meeting of the Royal Eye Hospital Clinícal Society held on November 5, 1943.

Mr. Holmes Smith, the Chairman, pointed out that considerable interest had been caused in ophthalmic circles by Dandy in his book on orbital tumours. He therein made the claim that the bulk of orbital tumours had intracranial extensions and should be dealt with by the neuro-surgeon through the transfrontal approach. Ophthalmic surgeons merely tinkered with the problem by explorations by Krönlein operations.

The Royal Eye Hospital Clinical Society wished to know the truth in this matter, and they had therefore asked a distinguished neurosurgeon to address them on the subject.

IN an accurate conception of the subject of " orbital tumours" material should bé restricted to those tumours developing primarily within the precincts of the orbital cavity. The subject, however, is so intimately related with that of " unilateral proptosis" that the inclusion of invasions by juxta-orbital tumours is not only permissible but essential. So limited is the incidence of primary tumours that the approach to the problem of the one-sided exophthalmos is broached with tumour-sense somewhat repressed. Rather has the problem been stressed unduly in its relationship with thyrotoxicosis. -

Two recent publications, Dandy's monograph on "Orbital Tumours,"' and a paper by Iles and Rendle Short, ${ }^{2}$ are of particular interest. Their material, together with personal cases; afford a fairly representative collection, though by no means pathologically inclusive. A study of this compounded list manifests certain outstanding features which are to be considered.

Well may one enquire as to what influencing factors direct patients to solicit advice and how the clinical diagnosis of " orbital tumour " is to be reached?

The most frequent and commonly the earliest symptom is unilateral proptosis, wherein there occurs a progressive, nonpulsatile, irreducible axial displacement of the affected eye. A proportion of patients proffer that the proptosis varies in degree; a matter possibly not difficult to understand, say, in the presence of a growth of the lacrimal gland, whereby interference with secretion would afford an explanation, but otherwise of doubtful causation.

Can proptosis per se be significant as a dominant, or even final factor in the diagnosis? Rundle and. Wilson, ${ }^{3}$ working at the Westminster Hospital Medical School, have investigated the subject and offer evidence on which they have deduced that a difference of six millimetres or more between the prominences of the two eyes is exclusive of other lesion than tumour. Moreover, 
these observers are of the opinion that something in the order of 90 per cent. of orbital tumours, on present-day diagnosis, exhibit this, or an even greater, degree of protrusion. Nevertheless it must not be assumed that invasion of the orbit by a tumour is indicated invariably in ocular protrusion-a point to which Dandy made particular comment in his reference to chiasmal gliomata. ${ }^{4}$ On the other hand, the development of proptosis in a case of intracranial neoplasm does not of necessity indicate extension of.tumour tissue into the orbital cavity.

Deviation of the eyeball in other directions is seen most often in a downward and outward displacement." This distortion the writer has encountered in tumour of the optic nerve, orbital pseudotumour, and mucocele of the frontal sinus.

In an analysis of individual symptoms encroachment on the incidence of proptosis is found in " visual disturbance." In fact, these two indicators, unilateral proptosis and defective vision, are often appreciated simultaneously. The form in which the visual derangement applies varies between deterioration of visual acuity, curtailment of the visual field and disruption of stereoscopic vision (diplopia). According to Parsons there is usually diplopia owing to interference with the mobility of the eye in optic nerve tumours. ${ }^{5}$ However, diplopia is by no means a common manifestation : whilst in some patients this doubtless arises out of a suppression of vision, central in origin, more frequently is this avoided by virtue of the severity of direct interference with visual acuity.

How singular it seems that protrusion of the eye and disturbances of vision fail in their early realisation by the victim; indeed appreciation of their existence may be purely accidental. Well may this be appreciated from the fact that in one of $\mathrm{my}$ patients awareness of the undue prominence of the eye was established during the trying on of hats at the milliner's, likewise a second patient noticed the paucity of visual acuity in attempting to sight a rifle in the course of Home Guard exercises.

How essiential it is for disturbances of vision to be analysed with 'care! A perfunctory dismissal of the visual fields as normal is not uncommon, whereas in reality a more meticulous examination, employing small test objects $(1$ and $2 \mathrm{~mm}$.) and a Bjerrum screen, may reveal some limited yet none the less significant déficiency, circumferential or insular. Timely recognition of an intracranial extension of a tumour may well be the outcome of such an investigation. Duke-Elder states that mural infiltration affects the visual acuity but not the visual fields. ${ }^{6}$

An occasional patient is distraught with pain, although pain fails to play any very prominent part in the average history. This somewhat surptising freedom from pain probably finds explanation in the chronicity of the majority of the lesions. That pain may 
hold important signification may be suspect from the outstanding part it played in one case under my care : by this one infers the likelihood that the underlying disease depends on an infective origin-a chronic granuloma or so-called "pseudo-tumour of the orbit."

The development of a mass discernible to the patient is of infrequent occurrence. More likely is it for a patient to observe an associated swelling of other parts, such as is found in the frontal or temporal region when a meningioma develops in the anterior fossa or about the sphenoidal ridge respectively. Some of the simple forms of tumour as seen in the more superficial planes of the orbit may gain early notice, e.g., dermoid cysts and tumours. of the lacrimal gland, According to Ridley and Sorsby, dermoids occurring at the outer and inner upper angles of the orbit, present as small, freely mobile tumours often containing hair. ${ }^{7}$ To assume, therefore, that these tumours are always apparent and rest in superficial planes would be erroneous; indeed, two personal cases showed no surface change, apart from proptosis, in any way related to the orbital outlet. The one patient exhibited swelling in the temporal fossa, and both afforded evidence of implication of deeper orbital planes on radiological examination.

The above complaints represent the more usual clinical signs. Amongst other reasons for the attendance of the patient are ptosis, oedema of the lids, chemosis, cranial nerve palsies, audible bruits, or, as in one personal case; the formation of a discharging sinus resultant on secondary infection.

What does the ophthalmoscope, reveal? 'Parsons in his "Diseases of the Eye" has condensed apparent changes in the statement that " papillitis may be present especially with optic nerve tumours, optic atrophy is common in other forms." 8 The material to hand confirms these impressions.

In the presence of tumours of the nerve papilloedema can reach high dimensions-the most advanced degrees observed personally in any case of cerebral or like tumour (12 to $13 \mathrm{D}$.): One of my cases depicted such change that it was not possible on clinical examination to differentiate between true papilloedema and a possible infiltrating state of the disc by tumour tissue.

Tumours arising primarily within the orbit either without, or within the muscle cone, have been productive of primary optic atrophy when any change has been discernible. With tumours invading the orbit, arising primarily in adjacent tissues, the disc changes have been found to represent those arising directly out of the primary lesion; hence sometimes primary atrophy is portrayed whilst at others there is papilloedema or consecutive atrophy. 
The' length of history may be astounding when fully established, but a true estimate is reached with difficulty owing to the failure of the change to engage the attention of the patient. Tumours of the nerve afford a history merely of weeks or perhaps months, but other tumours may, on revision, provide facts from which the duration may be gauged. A period of from twelve to twenty years is not exceptional. One patient previously mentioned as having noted the distortion of the eye when trying on hats, found the eye to be unusually prominent in a passport photograph that had been taken several years before.

How misrepresentative a small series of cases can be is evident in a reyiew of the material at hand. One recalls Dandy's five. cases of Schüller-Christian disease, Iles' and Rendle Short's four cases of haemangioma, and three cases of tumour of the optic nerve in my own experiences. That the diagnosis may be acceptable always is open to doubt, as incidenced in Schüller-Christian disease, for one personal case was reported on by another clinic as harbouring a tumour probably of such origin, the conclusions being formulated from a-biopsy specimen: The mass finally proved to be of an epidermoid nature. 'A field of the histological section is included in this paper,

A' review of ophthalmological literature is especially interesting, particularly in dealing with the problem of optic nerve tumours. Parsons states that most of these tumours are probably endotheliomata which have undergone degèneration. 9 Verification for such a comment is not forthcoming from the large series of cases collected by Hudson ${ }^{10}$ and Mathewson ${ }^{11}$.In 211 cases of optic nerve tumours reviewed by these ophthalmologists :-

170 or 80.56 per cent. were gliomata.

33 or 15.63 per cent. were endotheliomata.

8 or 3.8 per cent. were fibromata:

Various points of clinical differentiation between gliomata and endotheliomata are rendered, but confirmation cannot be established from the data to hand. Certainly glioma of the nerve is a disease of the young (average 13 years-Hudson) and much commoner than meningioma (6 to 1 -Mathewson). ${ }^{12}$

Radiological verification is forthcoming in a high percentage of cases of orbital tumour; manifest in erosion, sclerosis or hyperostosis of bone. From personal experiences it may be said that when the orbit is invaded from without, or when an orbital mass has extruded beyond the normal precincts of the orbit, radiographic confirmation is the rule. When a tumour produces expansion of the canalicular portion of the optic nerve the optic foramen enlarges, whereas mural infiltration encroaches upon the optic canal, thereby causing a concentric or irregular constriction. According to Clegg an optic canal measuring less than $2.8 \mathrm{~mm}$. 
in one of its diameters cannot contain a normal optic nerve. ${ }^{13}$ In the diagnosis of "optic nerve tumour" the importance of a circular enlargement of the foramen in contrast with other outlines should be stressed. That asymmetry in the two foramina may be present without pathological bearing should be fully realised, for Clegg's observations indicate that absolute symmetry is found in but 45 per cent. of skulls. ${ }^{14}$ Hudson has drawn attention to the fact that the optic foramen attains its full adult dimensions by the time a child reaches the age of three years..$^{15}$

Generally speaking, clinico-pathological investigations do not afford data in confirmation of tumours restricted to the orbit, excluding such rarities as cysts of parasitic origin.

The presence of Bence-Jones protein in the urine as evidence of myelomatosis would clinch suspicions in a case of generalised osseous disease with orbital deposits.

These considerations give some indication of the clinical-pathological aspects : the occasional fact, significant and assertive, yet of infrequent bearing. One essential examination in the presence of any lesion of expanding type is the Wassermann or comparable reaction.

Analysis of the cerebro-spinal fluid is commonly negative, but even this fact may be applied to contra-indicate the possibility of intracranial extension as by an optic nerve glioma (possible increase in total protein content when sub-arachnoid space is infringed). Again, the lack of protein in excessive quantities in the presence of an orbital mass with intracranial extension may bear pathological significance. (A meningeal tumour may cause considerable exudation of protein into the cerebro-spinal fluid, whereas an epidermoid would not induce such a change.)

The formation of an inflammatory mass may be associated with suggestive or confirmatory alterations in the blood picture, as would invasions of the orbit by certain -blood diseases.

Operative treatment having been elected, there remains the selection of the operative route to be adopted. Little difficulty arises when dealing with anteriorly and superficially placed lesions that lend themselves to easy exposure from the front and through the eyelid or the conjunctival sac. For the more deeply situated and so less easily approachable tumour the choice of exposure lies between the lateral route, or Krönlein type of attack; and the transcranial operation, wherein a frontal osteo-plastic flap is reflected, as in operations on the pituitary region, and the orbit explored through its roof.

In my opinion the Krönlein operation with the limited field it provides, the diplopia that so frequently ensues, and the unsightly scar that it leaves, has little to be offered in its favour. On behalf of the transcranial operation, the final scar 


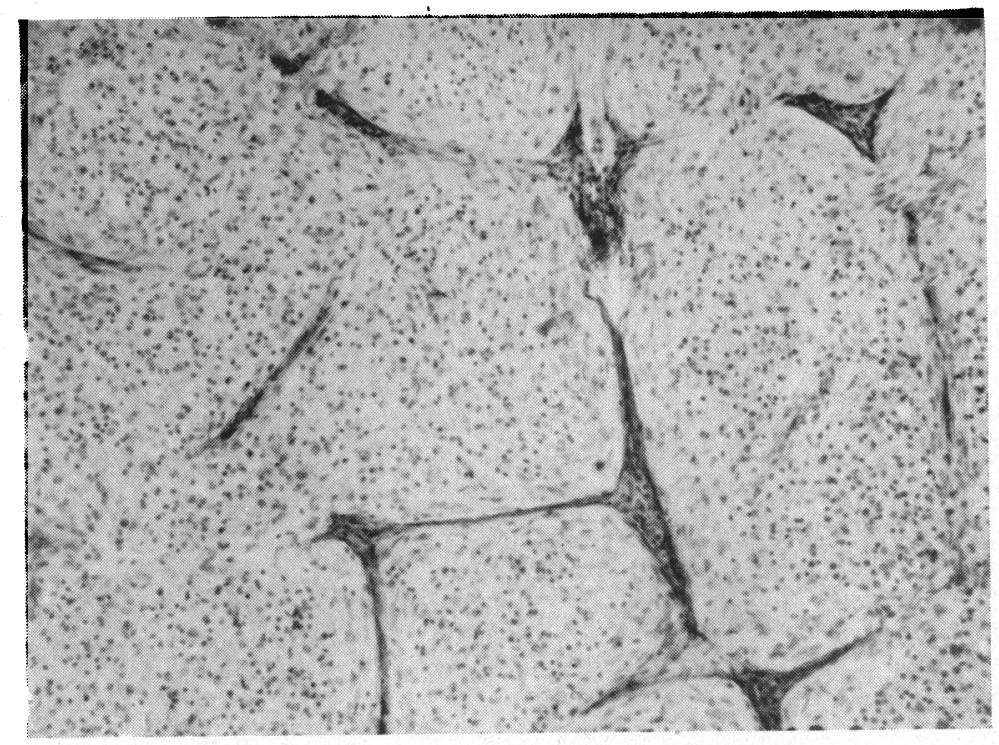

Section of glioma of the optic nerve (astrocytoma).

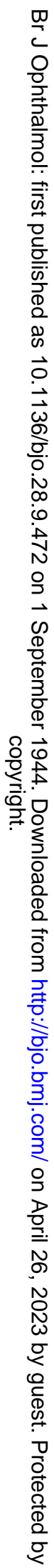




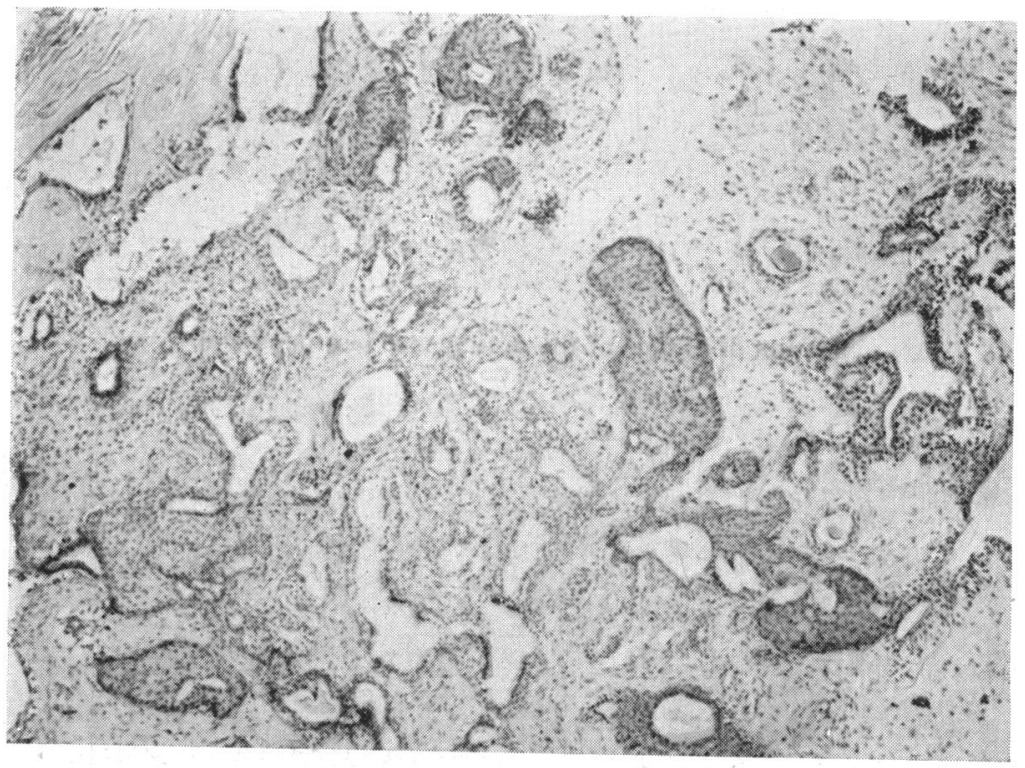

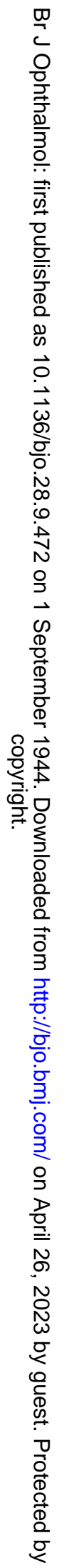




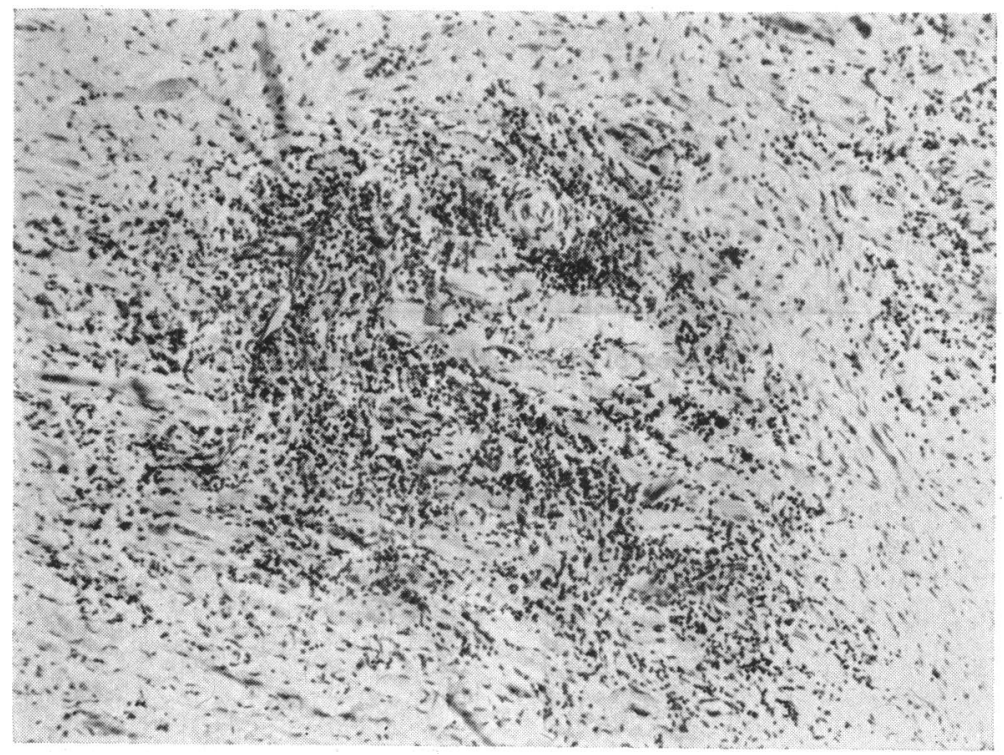

Section of a granuloma or pseudo-tumour of the orbit. 


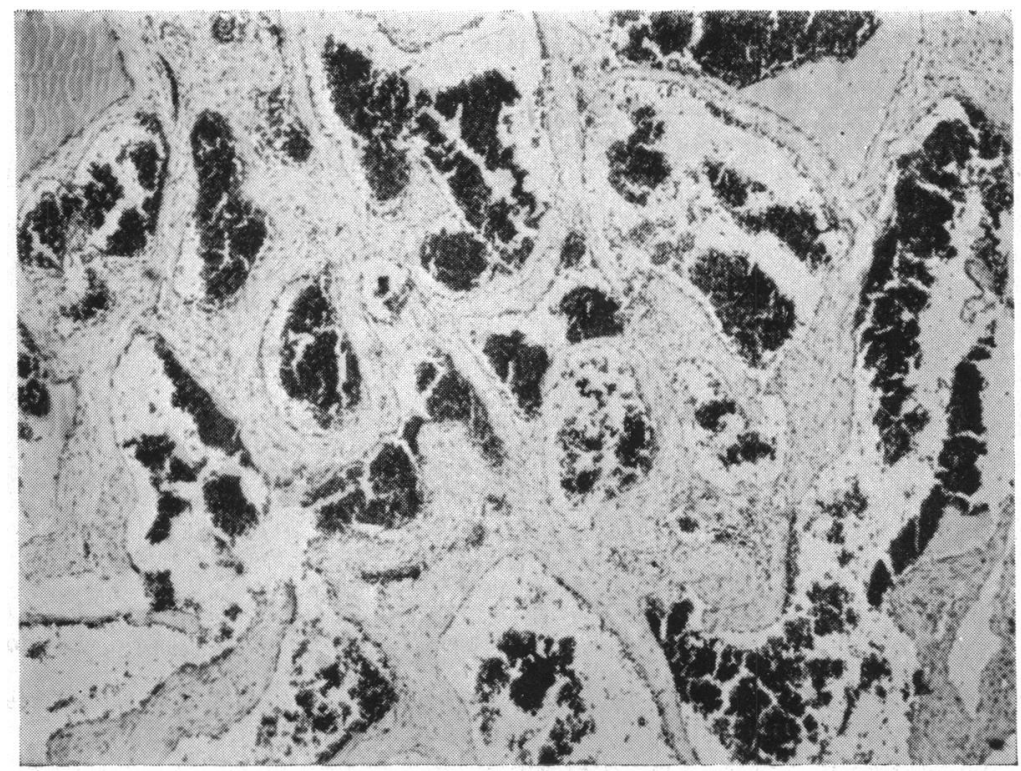

Section of haemangeioma of orbit.
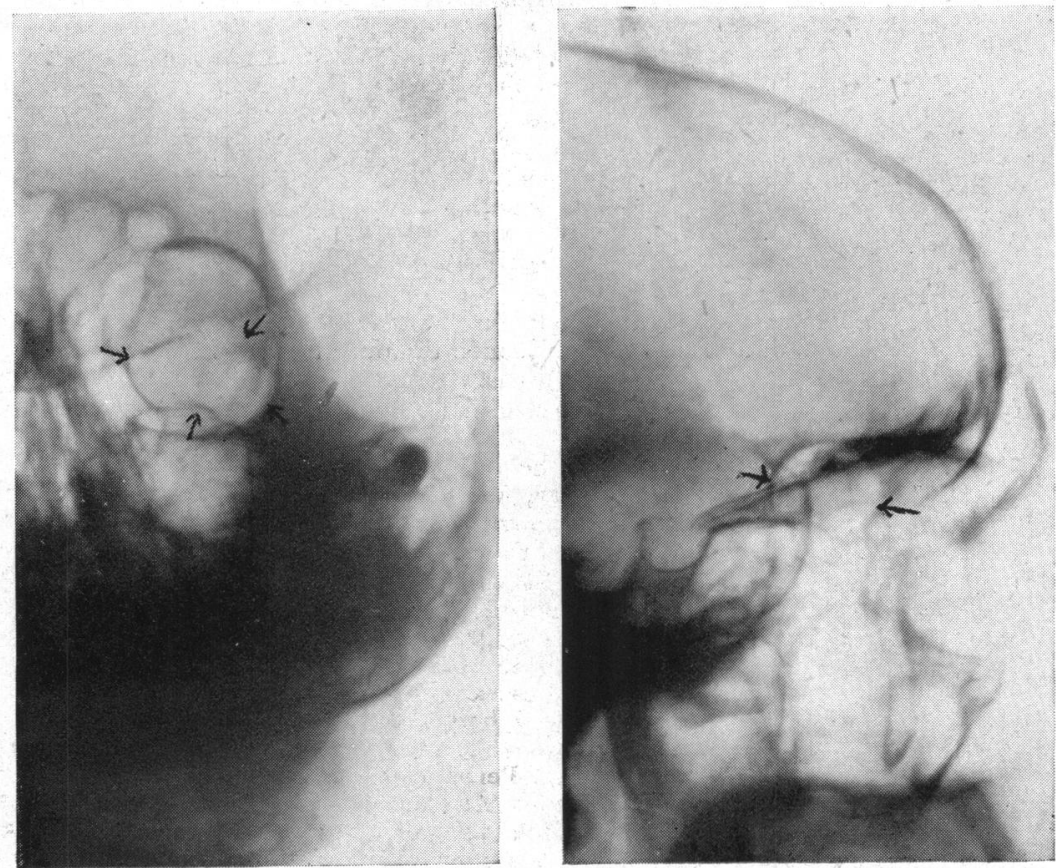

Radiographs showing erosions of the orbital wall by dermoid tumours.

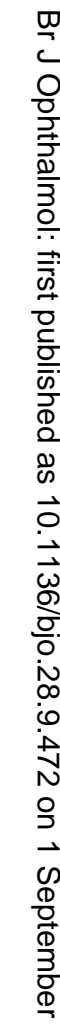$$
\stackrel{8}{0} \stackrel{0}{\grave{0}}
$$$$
\text { 흑웅 }
$$

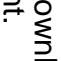$$
\text { 亏ํำ }
$$$$
\text { ำ }
$$$$
\text { 홍 }
$$$$
\text { 룽 }
$$$$
\text { 흥. }
$$$$
\text { 극 }
$$$$
\text { ธิ }
$$$$
\text { 오 }
$$$$
\text { 금 }
$$$$
\text { N }
$$$$
\text { 음 }
$$$$
\text { స్ }
$$$$
\text { ర }
$$$$
\text { 足 }
$$$$
\text { 뭉 }
$$ 
is completely hidden, a much wider exploration of the orbit is available, and for those cases wherein the tumour extends from beyond the orbit into the cranial cavity, no other mode of attack could prove adequate. The risk of this formidable undertaking has been cited as a contra-indication to its employment, but at the hands of a trained neurosurgeon this can be discounted. That an unsightly distortion of the eye of pulsatile character is the result is entirely false, as is apparent from the post-operative results demonstrated this evening.

\section{REFERENCES}

1. Dandy, Walter E. (1942).-Orbital Tumours. London.

2. Iles, A. E. and RENDLE Short, A. (1943).-Brit. Jl. Surg., Vol. XXXI, pp. 1.22-147.

3. RUNDLE, F. F. and WiLson, C. W.-Clinical Science. In preparation.

4. DANDY, WALTER E. (1942).-Orbital Tumours.

5. Parsons, Sir J. H. (1942).-Diseases of the Eye. London: J. and A. Churchill, Limited.

6. DUKE-ELDER, SIR W. S. (1940).-Text-book of Ophthalmology. London: Henry Kimpton.

7. Ridley, F. and Sorsby, A. (1933).-Mayou's Diseases of the Eye. Oxford University Press. London : Humphrey Milford.

8. Parsons, Sir J. H. (1942).-Diseases of the Eye.

9. Ibidem.

10. Hudson, A. C. (1912).-Roy. Lond. Ophthal. Hosp. Reps., Vol. XVIII, p. 317.

11. Mathewson, G. A. (1930).-Amer. Jl. of Ophthal., Vol. XIII, p. 381.

12. Ibidem.

13. CleGG, J. G. (1936).-Brit. Jl. of Ophthal., Vol. XX, p. 667.

14. Ibidem.

15. Hudson, A. C. (1912):-Roy. Lond. Ophthal. Hosp. Reps., Vol. XVIII, p. 317.

16. Goalwin, H. A. (1927).- Jl. Amer. Med. Assoc., Vol. LXXXIX, pp. 21, 1745.

Before the paper $\mathrm{Mr}$. Jackson demonstrated several interesting cases of orbital tumour. These included a child from whom he had removed a glioma of the optic nerve seven years previously. He also-showed a lady operated on in 1938 for an orbital astrocytoma. Another lady had had proptosis for twenty years with anaesthesia of the 5 th nerve area. He removed an epidermal tumour of orbit which extended back into the cranial cavity. He also showed a case in which a haemangioma of the left orbit had been successfully excised. In another case an orbital tumour had been diagnosed; but on operation nothing of the sort was found, but an optic nerve narrowed by inflammation.

Dr: Rundle demonstrated a case of Graves's disease in which one eye was more prominent. There was lid retraction with unilateral spasm of the levator palpebrae superiosis.

Mr. Lindsay Rea stated how much he had appreciated Mr. Harvey Jackson's lecture. He felt a feeling of humility, because among Mr. Harvey Jackson's cases he saw two who had been in his own charge years previously. He had not diagnosed orbital tumour at the time, though now the condition was obvious. $\mathrm{He}$ had recently assisted a well-known neurosurgeon in the removal of an orbital tumour, and he found himself being complimented on the great care he took of the eye. This seemed to surprise the surgeon, and he thought it showed how important it was for the neurosurgeon to have an ophthalmologist in intimate collaboration with him in these difficult cases.

Mr. L. H. Savin said he wished to say how much he had enjoyed the lecture. When he read Dandy's book he thought that the cases described were not quite an average sample of orbital tumours. Perhaps cases with intracranial involvement tended to get referred to Dandy. Mr. Savin privately thought he would continue to explore these cases by Krönlein's operation, with which he had been successful in five: cases in getting adequate exposure and removing the tumour.

After seeing Mr. Harvey Jackson's cases he saw he had been wrong. The cases just demonstrated were so yery much better than Krönlein cases from the 
cosmetic point of view. By the transfrontal route there was no ugly temporal scar as in his own cases.

Mr. Harvey Jackson had mentioned orbital dermoids, and he (Mr. Savin) had one in his own series. It -caused great proptosis, and unfortunately in the course of removal of the tumour he had produced a ptosis and weakness of the superior rectus, later rectified with great difficulty.

He had had a case of psammoma of the optic nerve sheath. He removed the tumour successfully, and later the patient developed symptoms from what turned out to be multiple intracranial meningiomata.

Mr. Harvey Jackson had mentioned pseudo-tumours of the orbit. Some time ago Mr. Savin was called to a municipal hospital to remove an eye in which there had been perforation of an infected corneal ulcer. The eye was much protruded, and after enucleation this was found to be due to a large rounded orbital swelling behind the.globe. Later investigation showed this to be a case of "pseudotumour."

Mr. Jackson had mentioned 5th nerve pain as a prominent feature in pseudotumours. He wondered if there was any connection with those cases of periostitis of the sphenoidal fissure which Dr. James Collier was so fond of demonstrating in the old days at the Royal Eye Hospital. In these cases there was severe 5th nerve pain, limitation of ocular movements, and often proptosis. He had seen them follow dental extractions and tonsillectomy.

Mr. Hughes spoke of difficulties in discriminating between orbital tumours and other causes of proptosis such as exophthalmic ophthalmoplegia. In tumour cases the fields were always affected. He had seen over twenty explorations of orbit by the transfrontal route. In Mr. Jackson's hands it was a safe procedure.

Mr. Harvey Jackson, in reply, said he whole-heartedly agreed with Mr. Lindsay Rea that the ophthalmologist was an indispensable person on a neurosurgical unit. He, too, had seen psammomata associated with meningiomata elsewhere. $\mathrm{He}$ thanked everybody for their kind remarks.

\section{BOOK NOTICE}

The Lighting of Schools, Principles of Good Lighting, The Lighting of Public Buildings. From The Illuminated Engineering Society, 32, Victoria Street, London, S.W.1. Price, $1 /$. each, 9/. a dozen, $\notin 3$ a hundred.

These pamphlets, illustrated by thumb nail sketches, have been published for the benefit of government departments, local authorities, borough engineers, architects and others engaged in solving the lighting problems which will arise in the period of post war reconstruction.

The pamphlet most valuable to the ophthalmic surgeon, is that dealing with the lighting of schools, since it contains among other useful information a table giving the illumination in foot candles recommended for various types of work. This is a matter about which we are often consulted, and expected to have some precise information. Hints are also given as to the proper situation and types of light sources, the treatment of surfaces.such as walls, ceilings and blackboards, and the maintenance of lamps and windows. It is not generally realised, for example, that the combined effect of the accumulation of dust and dirt on lighting fittings and on walls and ceilings, may reduce the available illumination by as much as $20-30$ per cent. in six weeks. 